\title{
Correction to: Automatically identifying social isolation from clinical narratives for patients with prostate Cancer
}

Vivienne J. Zhu ${ }^{1 *}$ D, Leslie A. Lenert ${ }^{1}$, Brian E. Bunnell ${ }^{1}$, Jihad S. Obeid ${ }^{1}$, Melanie Jefferson ${ }^{2}$ and

Chanita Hughes Halbert ${ }^{2}$

\section{Correction to: BMC Med Inform Decis Mak https://doi.org/10.1186/s12911-019-0795-y}

Following publication of the original article [1], the authors reported an error in one of the authors' names. In this Correction the incorrect and correct author name are shown. The original publication of this article has been corrected.

Originally the author name was published as:

- Chanita A Hughes-Halbert

The correct author name is:

- Chanita Hughes Halbert

\section{Author details}

'Biomedical Informatics Center, Medical University of South Carolina,

Chalrleston, SC, USA. ${ }^{2}$ Holling Cancer Center and Department of Psychiatry and Behavioral Sciences, Medical University of South Carolina, Charleston, SC, USA.

Received: 16 April 2019 Accepted: 16 April 2019

Published online: 25 April 2019

\section{Reference}

1. Zhu, et al. Automatically identifying social isolation from clinical narratives for patients with prostate Cancer. BMC Med Inform Decis Mak. 2019;19:43 https://doi.org/10.1186/s12911-019-0795-y.

\footnotetext{
*Correspondence: zhuv@musc.edu

${ }^{1}$ Biomedical Informatics Center, Medical University of South Carolina,

Chalrleston, SC, USA

Full list of author information is available at the end of the article
} 